\title{
Elastic Moduli of Nanoglasses and Melt-Spun Metallic Glasses by Ultrasonic Time-of-Flight Measurements
}

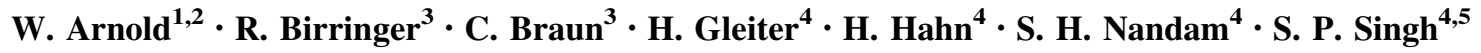

Received: 28 November 2019/Accepted: 5 April 2020/Published online: 13 May 2020

(C) The Author(s) 2020

\begin{abstract}
The elastic moduli of the metallic nanoglasses $\mathrm{Fe}_{86} \mathrm{Sc}_{14}, \mathrm{Fe}_{90} \mathrm{Sc}_{10}, \mathrm{Cu}_{58} \mathrm{Zr}_{42}$, and $\mathrm{Cu}_{60} \mathrm{Zr}_{40}$ were determined by measuring their longitudinal and shear wave velocities together with their densities. The data were compared to the elastic moduli of the conventional meltspun metallic glass counterparts of the same chemical composition. The elastic moduli for the nanoglasses were significantly smaller than those of the metallic glass counterparts. Finally, a comparison was made between the data for nanoglasses and metallic glasses from the literature.
\end{abstract}

Keywords Elasticity $\cdot$ Nanoglasses $\cdot$ Metallic glasses · Amorphous materials · Ultrasonics

W. Arnold

w.arnold@mx.uni-saarland.de

1 Fachrichtung Materialwissenschaft und Werkstofftechnik, Universität des Saarlandes, Campus D 2.2, 66123 Saarbrücken, Germany

2 I. Physikalisches Institut, Georg-August-Universität, 37077 Göttingen, Germany

3 Experimentalphysik, Universität des Saarlandes, Campus D 2.2, 66123 Saarbrücken, Germany

4 Institute of Nanotechnology, Karlsruhe Institute of Technology, P.O. Box 3640, 76021 Karlsruhe, Germany

5 Center for Ceramic Processing, International Advanced Research Center for Powder Metallurgy and New Materials, Hyderabad 500005, India

\section{Introduction}

Nanoglasses are non-crystalline materials with controlled modifications of their defect and/or chemical microstructure by methods that are comparable to those used for crystalline nanomaterials [1-4]. One way of introducing a high density of defects into crystals in the form of incoherent interfaces (grain boundaries) is by consolidating nanometer-sized crystals with identical or different chemical compositions. In these interfaces, a large number of atoms are present which affect the properties of materials to a great extent. In fact, it was proposed [1] to introduce a high volume of glass-glass interfaces by consolidating nanometer-sized glassy clusters with identical or different chemical compositions. Transmission electron microscopy, positron annihilation spectroscopy, wide and small angle X-ray diffraction, elemental mapping, scanning tunneling microscopy, atomic force microscopy, Mössbauer spectroscopy, and molecular dynamics simulations have elucidated the structural features of these nanoglasses [5]. The glassy core regions and the glass-glass interfacial regions of a nanoglass differ as far as their atomic and electronic structures are concerned. The Mössbauer spectrum of the glassy core regions of a $\mathrm{Fe}_{90} \mathrm{Sc}_{10}$ nanoglass is a single-line spectrum whereas the spectra of the amorphous interfacial regions consist of six lines, indicating that the glassy regions are paramagnetic whereas the interfaces are ferromagnetic at room temperature $(295 \mathrm{~K})$. The different electronic structures of the glassy and the interfacial regions of a nanoglass are not limited to $\mathrm{Fe}_{90} \mathrm{Sc}_{10}$ [6] but were also found for $\mathrm{Pd}_{72} \mathrm{Fe}_{10} \mathrm{Si}_{18}$, [1], $\mathrm{Fe}_{50} \mathrm{~B}_{50}$, [7] and various other $\mathrm{ScFe}$ nanoglasses [1, 7-14]. All these observations suggest a two-phase model for nanoglasses: in one phase, the glassy core regions, originates from the glassy clusters that were consolidated to prepare the 
nanoglass, thereby entailing the formation of the second phase in the interfaces between these glassy regions. All existing observations presently available about nanoglasses seem to indicate that this second phase represents a new state of non-crystalline matter [5].

The formations of a new, non-crystalline atomic structure (different from the atomic arrangement in a meltquenched glass) as well as a new electronic structure in the interfaces of nanoglasses may be understood as follows: If a nanoglass is generated by joining nanometer-sized glassy clusters, the interfaces between these glassy clusters contain regions with a locally enhanced free volume at which the atoms of the adjacent glassy clusters relax in order to minimize the free energy. The relaxation processes are expected to result in an enhanced thermal stability as well as in an enhanced medium-range order of the nanoglasses relative to melt-quenched glasses with the same chemical composition [5]. Moreover, the properties of these interfacial regions are expected to differ from the properties of melt quenched glasses with the same chemical compositions. Indeed, this expectation is confirmed by different experimental studies. For example, the glass transition temperature $\left(T_{\mathrm{g}}\right)$ as well as the crystallization temperature $\left(T_{\mathrm{x}}\right)$ of an $\mathrm{Au}_{52} \mathrm{Ag}_{5} \mathrm{Pd}_{2} \mathrm{Cu}_{25} \mathrm{Si}_{10} \mathrm{Al}_{6}$ nanoglass was reported to be about $25 \mathrm{~K}$ higher than those of the corresponding melt-cooled ribbon $[15,16]$. Measured by bending tests, the elastic modulus of this nanoglass with a cluster size of about $10 \mathrm{~nm}$ was $\sim 78.8 \mathrm{GPa}$ [16] which was about $10 \%$ higher than the elastic modulus of the corresponding bulk metallic glass [17, 18].

It is the goal of this study to measure with ultrasound the elastic moduli in the two non-crystalline materials of the same compositions such as $\mathrm{FeSc}$ and $\mathrm{CuZr}$ nanoglasses and their conventional melt-spun metallic glass counterparts and to elucidate whether there are systematic differences. All specimens are available in the as-prepared state. Apart from possible room temperature relaxation, intentional aging or rejuvenation has been omitted. We assume that both types of glassy materials behave as statistically isotropic and homogeneous. Based on this premise, we have extracted effective elastic moduli which we can compare with the presently available literature data. These moduli are high frequency moduli which have been derived from the determination of ultrasound velocities of shear and longitudinal waves generated by appropriate transducers in the materials.

\section{Experimental Set-Up for Measuring Ultrasonic Time-of-Flight Data}

Based on ultrasonic velocities, the elastic moduli can be determined both for isotropic as well as anisotropic materials [19]. Here, ultrasonic velocities are determined by two techniques: the pulse-echo technique employing a single delay-line transducer (so-called single ended or mono-static technique), Fig. 1a, or the ultrasonic transmission technique in order to measure the time delay through a sample sandwiched between two delay-line transducers (so-called double ended or bi-static technique), Fig. 1b. The ultrasonic signals are generated by two different electronic systems. One system, using an electrical spike generator, generates electric discharge pulses in a coaxial cable whose length determines the ultrasonic pulse-length which is $1-10 \mathrm{~ns}$ [20]. Such pulses can be used to excite an ultrasonic transducer. This technique is also called wideband excitation. In the second system, an rf-carrier system has been used as electronic transmitter whose carrier frequency varies from 20 to $200 \mathrm{MHz}$ and is adjusted to the resonance frequency of the transducer. The number of rfoscillations selected is typically $3-5$. This second technique is called narrow-band excitation. Further details can be found in the appendix.

If samples are sufficiently thick, pulse-echo experiments with well-separated echo patterns are easily obtained using wide-band excitation, allowing one to measure the time-offlight of the signals (Fig. 2a, b). Together with thickness measurements, this leads to the sound velocities for the longitudinal as well the shear waves. Knowing the specimen's densities, their elastic moduli and Poisson ratios can be derived. There are numerous measurement and signal processing techniques to obtain accurate sound velocity data and its frequency dispersion [21, 22]. Whereas the nanoglass samples examined here are thick enough $(>120 \mu \mathrm{m})$ to obtain echo patterns with clearly distinguished individual echoes (Fig. 2a, b), the metallic glass ribbon samples are only about $24-34 \mu \mathrm{m}$ thick and no separate echo pattern can be generated in these samples with standard pulse-echo experiments.

Systems such as laser ultrasonics with broad-band detection $[23,24]$ or piezoelectric ultrasonic systems with

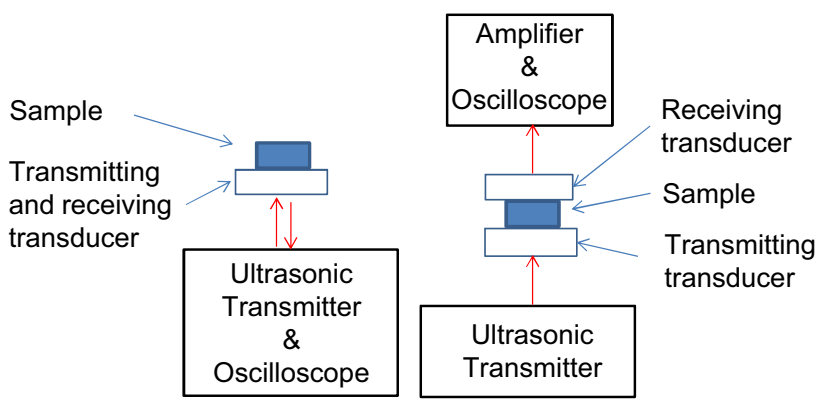

(a)

(b)

Fig. 1 a Pulse-echo system to obtain the sound velocity by measuring the time-of-flight between individual echoes; $\mathbf{b}$ principle of measurement for transmission experiments 
Fig. 2 a Longitudinal wave echo-pattern in the nanoglass $\mathrm{Fe}_{86} \mathrm{Sc}_{14}$. The time-of-flight difference between first two echoes is $0.175 \mu \mathrm{s}$; $\mathbf{b}$ shear wave echo-pattern in the nanoglass $\mathrm{Fe}_{86} \mathrm{Sc}_{14}$. The timeof-flight difference between the first two echoes is $0.331 \mu \mathrm{s}$
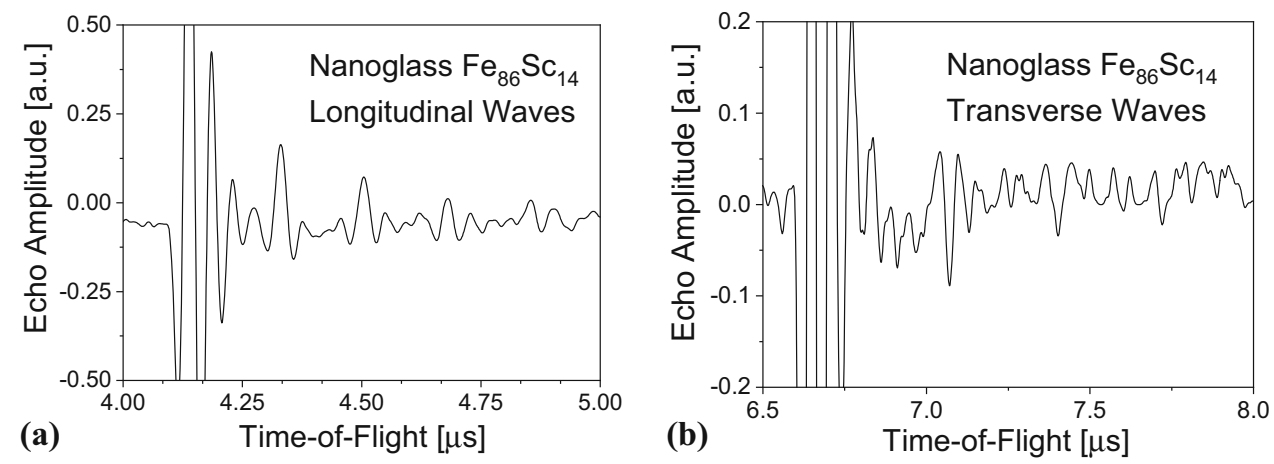

bandwidths in the order of $1 \mathrm{GHz}$ [20] are suitable for this task; however, they are not at our disposal.

\section{Materials and their Characterization}

The nanoglass samples were prepared using inert gas condensation (IGC) method equipped with in-situ compaction in an ultrahigh vacuum system. Thermal evaporation and sputtering techniques were used to produce the $\mathrm{Fe}_{100-\mathrm{x}} \mathrm{Sc}_{\mathrm{x}}$ $\left(\mathrm{Fe}_{86} \mathrm{Sc}_{14}, \mathrm{Fe}_{90} \mathrm{Sc}_{10}\right)$ and the $\mathrm{Cu}_{100-\mathrm{x}} \mathrm{Zr}_{\mathrm{x}}\left(\mathrm{Cu}_{58} \mathrm{Zr}_{42}, \mathrm{Cu}_{60}\right.$ $\mathrm{Zr}_{40}$ ) nanoglasses, respectively. In detail, this process entailed quenching with helium gas at a pressure of $0.5 \mathrm{mbar}$ to generate nanometer-sized glassy particles which were deposited on a liquid nitrogen cooled cold finger (cylindrical in shape) inside the inert gas filled chamber. The so-deposited nanoglass particles were collected in a holder and transferred into a hydraulic press followed by in-situ compaction at pressures of $3 \mathrm{GPa}$ for the $\mathrm{Fe}_{100-\mathrm{x}} \mathrm{Sc}_{\mathrm{x}}$ nanoglasses, whereas the compaction pressure was $1.3 \mathrm{GPa}$ and $6 \mathrm{GPa}$ for the two measured $\mathrm{CuZr}$ nanoglasses. The thicknesses $L$ of the produced nanoglasses $\mathrm{Fe}_{90} \mathrm{Sc}_{10}, \mathrm{Fe}_{86} \mathrm{Sc}_{14}, \mathrm{Cu}_{60} \mathrm{Zr}_{40}$, and $\mathrm{Cu}_{58 \mathrm{Zr} 42}$ were $0.338,0.470,0.126$, and $0.45 \mathrm{~mm}$, respectively, and their diameter was $\approx 8 \mathrm{~mm}$. For comparison, the metallic glasses $\mathrm{Fe}_{86} \mathrm{Sc}_{14}, \mathrm{Fe}_{90} \mathrm{Sc}_{10}$, and $\mathrm{Cu}_{60} \mathrm{Zr}_{40}$ having the same chemical composition were made by conventional melt-spinning technique in an inert atmosphere yielding ribbons with a thickness $L$ of $24-35 \mu \mathrm{m}$ which was measured with a precision of $\pm 1 \mu \mathrm{m}$ using a dial gauge made by Käfer, Villingen-Schwenningen, Germany. The densities of the nanoglass as well as the melt-spun glass samples were determined by the method of Archimedes. To this end, a microbalance Sartorius R160P with a resolution of $0.01 \mathrm{mg}$ was used to measure the mass $G_{\mathrm{m}}$ of the samples in the reference media air and diethyl phthalate (DEP) separately. Each measurement was repeated five times in the case of air and ten times in the case of DEP. Based on the mean values $G_{\text {air }}$ and $G_{\text {DEP }}$, the bulk density $\rho_{\text {bulk }}$, i.e. the density of the sample including its closed porosity, can be calculated according to [25] $\rho_{\text {bulk }}=\frac{G_{\text {air }}}{\left(G_{\text {air }}-G_{\text {DEP }}\right)}\left(\rho_{\text {DEP }}-\rho_{\text {air }}\right)+\rho_{\text {air }}$,

where $\rho_{\text {air }}$ and $\rho_{\text {DEP }}$ denote the density of air and DEP, respectively. All experimental data obtained for the thickness $L$ and the bulk density $\rho_{\text {bulk }}$ of the samples are listed in the columns 2 and 3 of Tables 1, 2 .

\section{Time-of-Flight Data}

For all four nanoglass samples, where a clear echo pattern with multiple echoes was obtained, measurements were carried out at least 4 times, some up to 10 times. The timeof-flight data were averaged, and these values were then used to compute the sound velocities listed in Table 1 . As an example, pulse-echo patterns are shown in Fig. 2 for the $\mathrm{Fe}_{86} \mathrm{Sc}_{14}$ sample, both for longitudinal and for shear waves. As can be seen from the echo-patterns, the time-of-flight between first two echoes was $\Delta t_{\mathrm{L}}=0.175 \mu$ s for longitudinal waves (Fig. 2a) and $\Delta t_{\mathrm{T}}=0.331 \mu$ s for shear waves (Fig. 2b) corresponding accidentally to the mean values. The thickness $L$ of the sample was $L=0.47 \mathrm{~mm}$. These data yielded a sound velocity of $v_{\mathrm{L}}=2 L / \Delta t_{\mathrm{L}}=5.37 \mathrm{~mm} /$ $\mu \mathrm{s}=5.37 \mathrm{~km} / \mathrm{s}$ and a shear or transverse wave velocity of $v_{\mathrm{T}}=2 L / \Delta t_{\mathrm{T}}=2.84 \mathrm{~mm} / \mu \mathrm{s}=2.84 \mathrm{~km} / \mathrm{s}$. These measurements were repeated using the transmission technique described above as a test run for the measurements of the thin metallic-glass ribbons. The same velocity values were obtained within the measurement accuracy.

In the case of the $\mathrm{Fe}_{90} \mathrm{Sc}_{10}, \mathrm{Fe}_{86} \mathrm{Sc}_{14}$, and $\mathrm{Cu}_{60} \mathrm{Zr}_{40}$ metallic-glass ribbon samples, the delays of the signals were measured at least 10 times with different ribbon sections and the computed averaged sound velocities are listed in Table 2. For example, for the $\mathrm{Fe}_{90} \mathrm{Sc}_{10}$ sample, a delay of $\Delta t_{\mathrm{L}}=4.2 \mathrm{~ns}$ was measured for longitudinal waves for a thickness of $25 \mu \mathrm{m}$ (Fig. 3). This resulted in $v_{\mathrm{L}}$ $=5.95 \mathrm{~mm} / \mu \mathrm{s}$. Averaged over all measurements carried out, we obtained $v_{\mathrm{L}}=5.7 \pm 0.7 \mathrm{~mm} / \mu \mathrm{s}$. Similarly, we found for shear waves $v_{\mathrm{T}}=3.1 \pm 0.4 \mathrm{~mm} / \mu \mathrm{s}$. Finally, we are aware that there is dispersion in the signals which 
Table 1 Results for the disk-shaped nanoglass samples with thickness $L$ and bulk density $\rho_{\text {bulk }}$

\begin{tabular}{|c|c|c|c|c|c|c|c|c|}
\hline Nanoglass material & $L(\mathrm{~mm})$ & $\rho_{\text {bulk }}\left(\mathrm{g} / \mathrm{cm}^{3}\right)$ & $v_{\mathrm{L}}(\mathrm{mm} / \mu \mathrm{s})$ & $v_{\mathrm{T}}(\mathrm{mm} / \mu \mathrm{s})$ & $v$ & $G(\mathrm{GPa})$ & $E(\mathrm{GPa})$ & $E_{\mathrm{r}}(\mathrm{GPa})$ \\
\hline $\mathrm{Fe}_{90} \mathrm{Sc}_{10}$ & $0.338 \pm 0.001$ & $6.13 \pm 0.01$ & $4.61 \pm 0.05$ & $2.50 \pm 0.02$ & $0.291 \pm 0.009$ & $38.3 \pm 0.7$ & $99 \pm 5$ & $108 \pm 5$ \\
\hline $\mathrm{Fe}_{86} \mathrm{Sc}_{14}$ & $0.470 \pm 0.001$ & $6.22 \pm 0.02$ & $5.37 \pm 0.04$ & $2.84 \pm 0.02$ & $0.306 \pm 0.005$ & $50.2 \pm 0.7$ & $131 \pm 4$ & $145 \pm 4$ \\
\hline $\begin{array}{l}\mathrm{Cu}_{60} \mathrm{Zr}_{40} \text { (compaction at } 1.3 \\
\mathrm{GPa} \text { ) }\end{array}$ & $0.126 \pm 0.001$ & $6.9 \pm 0.6$ & $4.9 \pm 0.1$ & $2.32 \pm 0.04$ & $0.35 \pm 0.01$ & $37 \pm 5$ & $100 \pm 16$ & $114 \pm 18$ \\
\hline $\begin{array}{l}\mathrm{Cu}_{58} \mathrm{Zr}_{42} \text { (compaction at } 6 \\
\mathrm{GPa} \text { ) }\end{array}$ & $0.450 \pm 0.001$ & $6.859 \pm 0.005$ & $4.63 \pm 0.13$ & $2.26 \pm 0.06$ & $0.344 \pm 0.005$ & $35.0 \pm 0.8$ & $94 \pm 2$ & $107 \pm 3$ \\
\hline
\end{tabular}

The ultrasonic velocities for longitudinal waves $\left(v_{\mathrm{L}}\right)$ and shear waves $\left(v_{\mathrm{T}}\right)$ were measured using the pulse-echo technique. The values for Poisson ratio $v$, shear modulus $G$, Young's modulus $E$, and reduced Young's modulus $E_{\mathrm{r}}$ were calculated according to Eqs. (2)-(5)

Table 2 Results for the metallic glass ribbons with the same composition as the nanoglasses in Table 1

\begin{tabular}{lllllllll}
\hline Metallic glass material & $L(\mathrm{~mm})$ & $\rho_{\text {bulk }}\left(\mathrm{g} / \mathrm{cm}^{3}\right)$ & $v_{\mathrm{L}}(\mathrm{mm} / \mu \mathrm{s})$ & $v_{\mathrm{T}}(\mathrm{mm} / \mu \mathrm{s})$ & $v$ & $G(\mathrm{GPa})$ & $E(\mathrm{GPa})$ & $E_{\mathrm{r}}(\mathrm{GPa})$ \\
\hline $\mathrm{Fe}_{90} \mathrm{Sc}_{10}$ & $0.025 \pm 0.001$ & $6.95 \pm 0.06$ & $5.7 \pm 0.7$ & $3.1 \pm 0.4$ & $0.29 \pm 0.01$ & $67 \pm 18$ & $173 \pm 38$ & $189 \pm 40$ \\
$\mathrm{Fe}_{86} \mathrm{Sc}_{14}$ & $0.024 \pm 0.001$ & $7.0 \pm 0.5$ & $5.7 \pm 0.6$ & $3.0 \pm 0.4$ & $0.31 \pm 0.01$ & $63 \pm 20$ & $167 \pm 40$ & $184 \pm 42$ \\
$\mathrm{Cu}_{60} \mathrm{Zr}_{40}$ & $0.034 \pm 0.001$ & $7.64 \pm 0.05$ & $5.1 \pm 0.7$ & $2.2 \pm 0.4$ & $0.39 \pm 0.01$ & $38 \pm 10$ & $107 \pm 21$ & $126 \pm 22$ \\
\hline
\end{tabular}

The samples were provided as ribbons with a width of about $4 \mathrm{~mm}$ and thickness $L$. The listed ultrasonic velocities were measured using the transmission technique

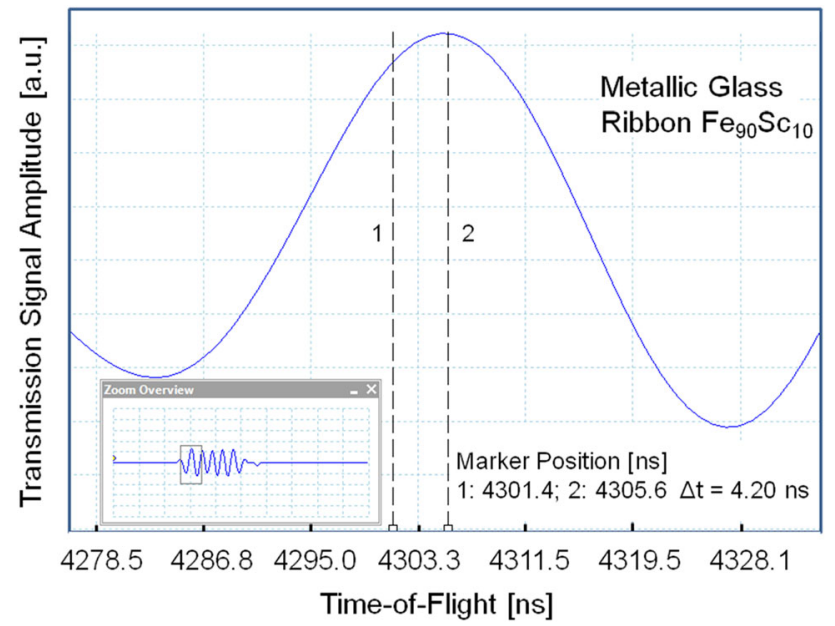

Fig. 3 Through-transmission signal for longitudinal waves in the metallic glass ribbon sample $\mathrm{Fe}_{90} \mathrm{Sc}_{10}$ with a thickness of $25 \mu \mathrm{m}$ (insert on the bottom left side). The vertical line 1 represents the position of the first maximum without the ribbon sample sandwiched between the two transducers. Then, after mounting the sample, the maximum shifted to the position of line 2 . The time difference between the lines corresponds to a delay of $\Delta t \approx 4.2 \mathrm{~ns}$. For the ribbon samples, at least ten measurements have been made in this way in order to reduce the statistical error, see Sect. 6. The carrier frequency is $23.9 \mathrm{MHz}$

contributes to inaccuracies. As shown in the appendix, uncertainties related to dispersion are small and can be neglected in the realm of this study.

\section{Data Evaluation}

It is straightforward to calculate from the measured sound velocities for longitudinal $\left(v_{\mathrm{L}}\right)$ and shear waves $\left(v_{\mathrm{T}}\right)$, the Poisson ratio $v$ without further information [21]. It is given by:

$v=\frac{v_{L}^{2}-2 v_{T}^{2}}{2\left(v_{L}^{2}-v_{T}^{2}\right)}$.

Furthermore, the shear modulus, $G$, and the Young's modulus, $E$, can be calculated from the measured velocities using [21]:

$G=\rho v_{\mathrm{T}}^{2}$.

$E=2(1+v) G$.

Finally, the reduced elastic modulus, $E_{\mathrm{r}}$, can be calculated as well:

$1 / E_{\mathrm{r}}=\left(1-v^{2}\right) / E$.

All derived elastic modulus values are listed in the four last columns of Tables 1, 2.

\section{Measurement Accuracy}

The accuracy of the computed data for elastic moduli and Poisson ratios is determined: (i) by the accuracy of the time-of-flight measurement of the ultrasonic signals with the oscilloscope's time delay markers $(\Delta t)$, (ii) by the 
accuracy of the thickness measurement of the samples $(\Delta L)$, and (iii) by the accuracy of the density measurement which relates to uncertainties $\Delta G_{\mathrm{m}}$ of sample mass in the different media (air, DEP). By calibration tests, we determined $\Delta t=1 \mathrm{~ns}$ and $\Delta L=1 \mu \mathrm{m}$. The accuracy of the density measurement was determined individually for each sample because their mass varied considerably from sample to sample. In Tables $1,2, v_{\mathrm{L}}, v_{\mathrm{T}}$, and $\rho$ are listed as source data with error margins. The computed values for $G$, $E$, and $v$ were obtained from the averaged sound velocity measurements, and the error margins were calculated according to the law of error propagation by assuming that uncertainties were independent and random.

For the nanoglasses $\mathrm{Cu}_{60} \mathrm{Zr}_{40}$ and the metallic glass ribbons $\mathrm{Fe}_{86} \mathrm{Sc}_{14}$, the main errors are due to the small mass at our disposal. For the sound velocity measurements, the errors for the metallic glass ribbon samples are due to the small thicknesses entailing a small signal time-of-flight with the corresponding error.

\section{Results and Discussion}

We refer to Tables 1, 2 and begin with a comparison of the $\mathrm{Fe}_{100-\mathrm{x}} \mathrm{Sc}_{\mathrm{x}}$ nanoglass samples (Table 1). Since a Sc crystal has a much lower density $\left(\rho_{\mathrm{Sc}}=2.982 \mathrm{~g} / \mathrm{cm}^{3}\right)$ compared to $\mathrm{Fe}\left(\rho_{\mathrm{Fe}}=7.874 \mathrm{~g} / \mathrm{cm}^{3}\right)$, we would expect that the density of the $\mathrm{Fe}_{86} \mathrm{Sc}_{14}$ sample should be lower than the $\mathrm{Fe}_{90} \mathrm{Sc}_{10}$ sample. Since we observe the opposite behavior, it seems obvious that a different preparation history and processing may have caused this counterintuitive result. Based on this reasoning, an enhanced longitudinal and transverse sound velocity is to be expected. In fact, we observe an about $30 \%$ increased $G$ - $(\approx 50 \mathrm{GPa})$ and $E$-value $(\approx 131 \mathrm{GPa})$ for $\mathrm{Fe}_{86} \mathrm{Sc}_{14}$ compared to $\mathrm{Fe}_{90} \mathrm{Sc}_{10}$ that is characterized by $G \approx 38 \mathrm{GPa}$, and $E \approx 99 \mathrm{GPa}$.

For comparison with conventional metallic glasses prepared by melt-spinning, we refer to the $\mathrm{Fe}_{86} \mathrm{Sc}_{14}$ and $\mathrm{Fe}_{90} \mathrm{Sc}_{10}$ specimens listed in Table 2. Surprisingly, the nanoglass $\mathrm{Fe}_{90} \mathrm{Sc}_{10}$ exhibits more than $40 \%$ decreased $G$ and $E$-moduli compared to the corresponding metallic glass ribbons, whereas the moduli of the $\mathrm{Fe}_{86} \mathrm{Sc}_{14}$ nanoglass are only reduced by about $20 \%$ compared to the $\mathrm{Fe}_{86} \mathrm{Sc}_{14}$ ribbons. Considering the fairly large error margin of the glassy ribbon materials, it seems nevertheless fair to conclude that the investigated nanoglasses evidence distinctly reduced moduli compared to their conventional metallic glass counterparts with the same chemical composition. This tendency is also true for the reduced Young's modulus $E_{\mathrm{r}}$ and more pronounced compared to the $E_{\mathrm{r}}$-values obtained by nanoindentation as shown in Table 3 .

We come back to the striking observation of a still $40 \%$ reduction of moduli values for the $\mathrm{Fe}_{90} \mathrm{Sc}_{10}$ nanoglass when comparing to its glassy ribbon counterpart. Assuming a linear rule of mixture and referring to density values of crystalline $\mathrm{Fe}$ and $\mathrm{Sc}$ as a reference, we find an alloy density of a fictitious crystalline $\mathrm{Fe}_{90} \mathrm{Sc}_{10}$ solid solution of $\rho_{\mathrm{Fe} 90 \mathrm{Sc} 10}=7.38 \mathrm{~g} / \mathrm{cm}^{3}$. Comparison with the density of the $\mathrm{Fe}_{90} \mathrm{Sc}_{10}$ metallic glass ribbon $\rho_{\mathrm{Fe} 90 \mathrm{Sc} 10}=6.95 \mathrm{~g} / \mathrm{cm}^{3}$ reveals a $6 \%$ decrease, which is typical for metallic glasses prepared by avoiding crystallization through fast cooling (typically $10^{5} \mathrm{~K} / \mathrm{s}$ ) the supercooled melt below the glass transition temperature [26]. Likewise, estimating the shear modulus of the fictitious alloy by a rule of mixture using $G_{\mathrm{Fe}}=82 \mathrm{GPa}$ and $G_{\mathrm{Sc}}=29 \mathrm{GPa}$, a value of 76.7 GPa is obtained for the alloy implying a reduction of the glassy ribbon by about $10 \%$ compared to the fictitious crystalline reference state. Such magnitude of reductions has been observed for a great majority of binary and ternary metallic glasses [26]. Therefore, we have confidence in the density and moduli data of the $\mathrm{Fe}_{90} \mathrm{Sc}_{10}$ metallic glass ribbon material (Table 2). In what follows, we associate a reference state with the metallic glass ribbon material which we refer to when discussing the properties of the nanoglasses. We note that the ribbons should have a pronounced potential for aging thereby reducing stored enthalpy and as a consequence contributing to enhanced values for density and moduli [27]. As a result, the property changes of nanoglasses computed with reference to metallic glass ribbons in this study have to be understood as lower bound estimates of the true property changes.

In principle, the massive reduction of moduli seen for the $\mathrm{Fe}_{90} \mathrm{Sc}_{10}$ nanoglass may have its origin in the proposed new state of non-crystalline matter in the interfaces of nanoglasses. Caused by a completely different effect, modulus reduction could also relate to porosity, which is known being present in IGC-prepared nanomaterials and contributes to measuring reduced effective moduli. Of course, a mixture of both scenarios or even a more complex microstructure may be at the origin of the reduction of effective moduli. Since the overall density reduction of $\mathrm{Fe}_{90} \mathrm{Sc}_{10}$ nanoglass compared to metallic $\mathrm{Fe}_{90} \mathrm{Sc}_{10}$ glass ribbon amounts to about $12 \%$, it is in order to scrutinize whether or not porosity accounts for modulus reduction. In fact, the effect of open and closed porosity on the elastic behavior of IGC-prepared nanocrystalline NiAl has been studied in detail [25].

Suggested by this study, let us for the sake of argument assume that the observed density reduction of $\mathrm{Fe}_{90} \mathrm{Sc}_{10}$ nanoglass has its origin mainly in porosity related to sample preparation by IGC and compaction (preparation history and processing). With this premise, we may adopt the way of data analysis discussed in detail in [25]. For the effective shear modulus of the $\mathrm{Fe}_{90} \mathrm{Sc}_{10}$ nanoglass $\mathrm{G}_{\mathrm{NG}}$ having porosity $P$ in excess to the $\mathrm{Fe}_{90} \mathrm{Sc}_{10}$ metallic glass ribbon material, characterized by $\mathrm{G}_{\mathrm{MGR}}$, we refer to the relation $[28,29]$.

$G_{\mathrm{NG}}=(1-a P)^{n} G_{\mathrm{MGR}}$.

The constant a is related to the packing geometry of pores 


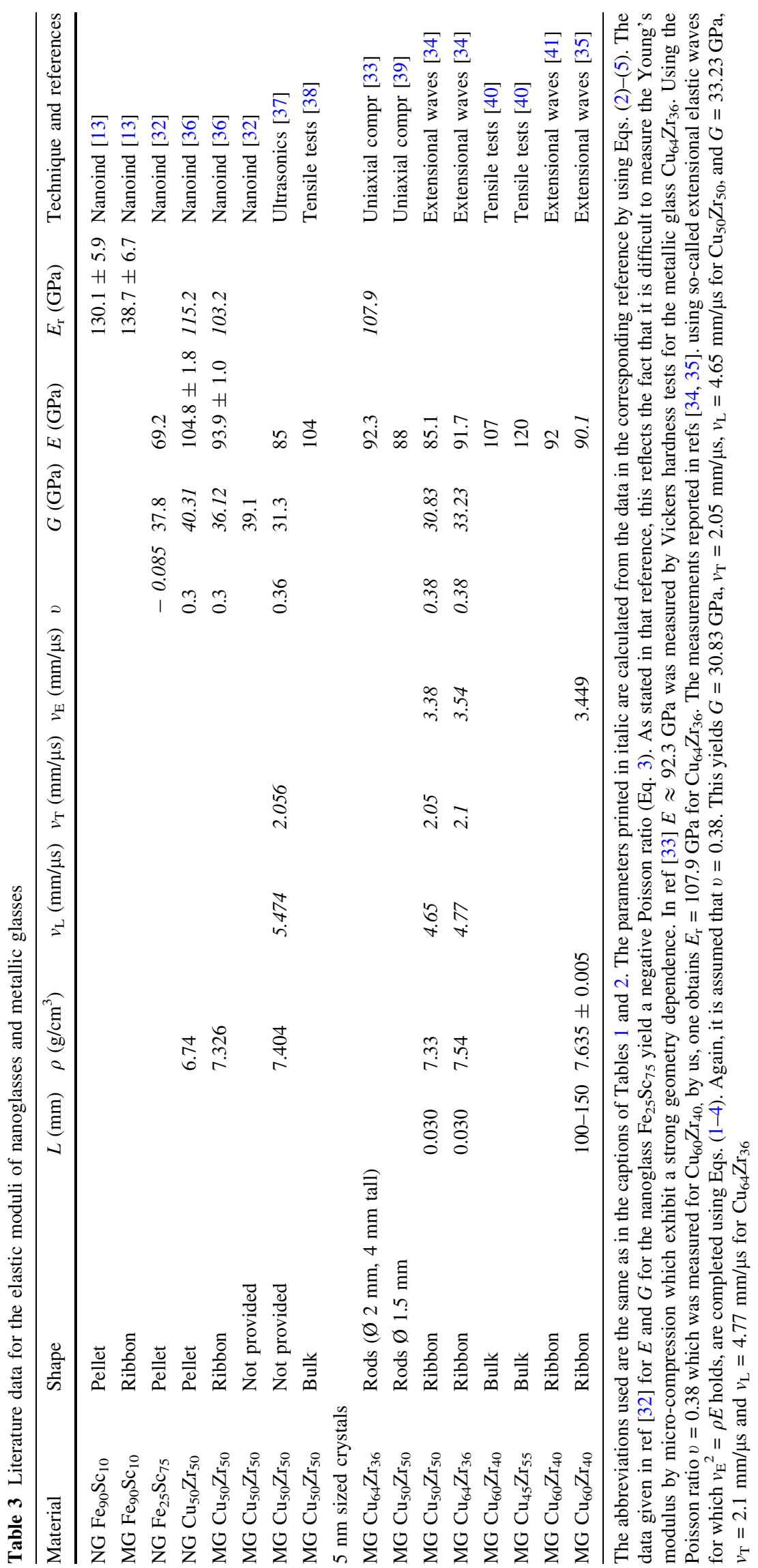


and $n$ depends on the grain morphology and pore geometry of the material and is determined to $n \approx 3$ [25], indicating that pores are interconnected. We assume $a \approx 1$ thus implying that ordered packing of pores is absent [28, 29]. The effect of porosity on the elastic modulus in solid materials has been reported experimentally by many groups, see for example ref.[30], as well as theoretically [31]. All relations known for $E(P)$ and $G(P)$ are similar to Eq. 6.

Using the values for $G_{\mathrm{NG}}$ and $G_{\mathrm{MGR}}$ from Tables 1,2 and solving for $P$, we obtain a value for porosity amounting to $P \approx 17 \%$. Since porosity contributes to a reduced density of a given material, it can be defined as $P=1-\rho_{\text {bulk }} / \rho_{\text {MGR }}$, where $\rho_{\text {bulk }}$ refers to the density of the nanoglass including its closed porosity (cf. Equation 1) and $\rho_{\mathrm{MGR}}$ represents the density of the metallic glass ribbon. The latter value is considered as (pore-free) reference state. Utilizing the measured values given in Tables 1,2 , we can compute the amount of porosity $P \approx 12 \%$ in the nanoglass sample. We refrain from varying the parameter $n$ in Eq. 6 to obtain a match for both values. We rather interpret the $P$-values independently obtained from the density and the sound wave velocity measurements as additional evidence for the prevalence of porosity in the order of $10 \%$.

To further validate this finding, we have prepared the $\mathrm{Fe}_{90} \mathrm{Sc}_{10}$ nanoglass specimen for SEM analysis. In order to remove surface contaminations, the sample is ion-beam polished for $120 \mathrm{~min}$ using a Hitachi IM4000 $(2.5 \mathrm{kV}$ accelerating voltage, $40 \mu \mathrm{A}$ beam current, $5^{\circ}$ inclination angle). The representative micrograph shown in Fig. $4 \mathrm{a}$ clearly reveals an appreciable amount of interconnected porosity. We like to point out that mechanical grinding and polishing of ion-beam polished samples make the observed porosity disappear in the SEM. However, reapplication of ion-beam polishing on such samples reveal in turn porosity as shown in Fig. 4a. From the whole set of micrographs analyzed, we deduce a fraction of closed porosity that varies between 10 and $15 \%$. As a result, we conclude that the porosity revealed by SEM is fairly comparable with the overall porosity determined by the analysis of elastic modulus reduction discussed above (cf. Equation 6). As a consequence, we conclude that there is not much room for assigning property changes to the proposed new state of non-crystalline matter in the interfaces of nanoglasses.

Regarding the $\mathrm{Cu}_{60} \mathrm{Zr}_{40}$ sample, we observe similar trends. However, due to the error margins, a straightforward comparison between differently prepared and measured specimens is difficult. In fact, we find for the Young's modulus of the $\mathrm{Cu}_{60} \mathrm{Zr}_{40}$ nanoglass, either slightly enhanced values if compared to literature data (Table 3 ) or reduced values if compared with data from own measurements (Table 2). This holds even for the $\mathrm{Cu}_{58} \mathrm{Zr}_{42}$ sample which has been compacted at much higher compaction pressure of $6 \mathrm{GPa}$. Because this sample has a larger mass, its density can be determined with a higher accuracy and therefore its elastic data. It is remarkable that the higher compacting pressure of $\mathrm{Cu}_{58} \mathrm{Zr}_{42}$ does not lead to an increase of the $G$ and $E$ values in comparison with the $\mathrm{Cu}_{60} \mathrm{Zr}_{40}$ sample (Table 1). Also, it still shows a residual porosity of $\approx 10 \%$ (Fig. $4 \mathrm{~b}$ ). Note that unlike our own measurements, the literature data does not provide a complete set of values for $G, E$, and $v$.

\section{Summary and Conclusions}

In summary, the ultrasonic measurements show that the elastic moduli of the nanoglasses $\mathrm{Fe}_{86} \mathrm{Sc}_{14}$ and $\mathrm{Fe}_{90} \mathrm{Sc}_{10}$ are significantly reduced compared to their metallic glass counterparts. For the $\mathrm{Fe}_{90} \mathrm{Sc}_{10}$ nanoglass, we can verify that the change in elastic properties is predominantly related to sample porosity. Within the given error margins, it is impossible to extract information about the proposed new state in the interfaces of nanoglasses which should entail enhanced elastic moduli. The literature data, displayed in
Fig. 4 a Backscatter micrograph of the surface of the nanoglass $\mathrm{Fe}_{90} \mathrm{Sc}_{10}$ sample taken in a Jeol SEM 7000F after ion-beam polishing (Hitachi IM4000, $2.5 \mathrm{kV}$ accelerating voltage, $40 \mu \mathrm{A}$ beam current, $5^{\circ}$ inclination angle, $120 \mathrm{~min}$ ) to remove surface contaminations. The dark areas correspond to pores; $\mathbf{b}$ backscatter micrograph of the surface of the nanoglass $\mathrm{Cu}_{58} \mathrm{Zr}_{43}$ compacted at $6 \mathrm{GPa}$
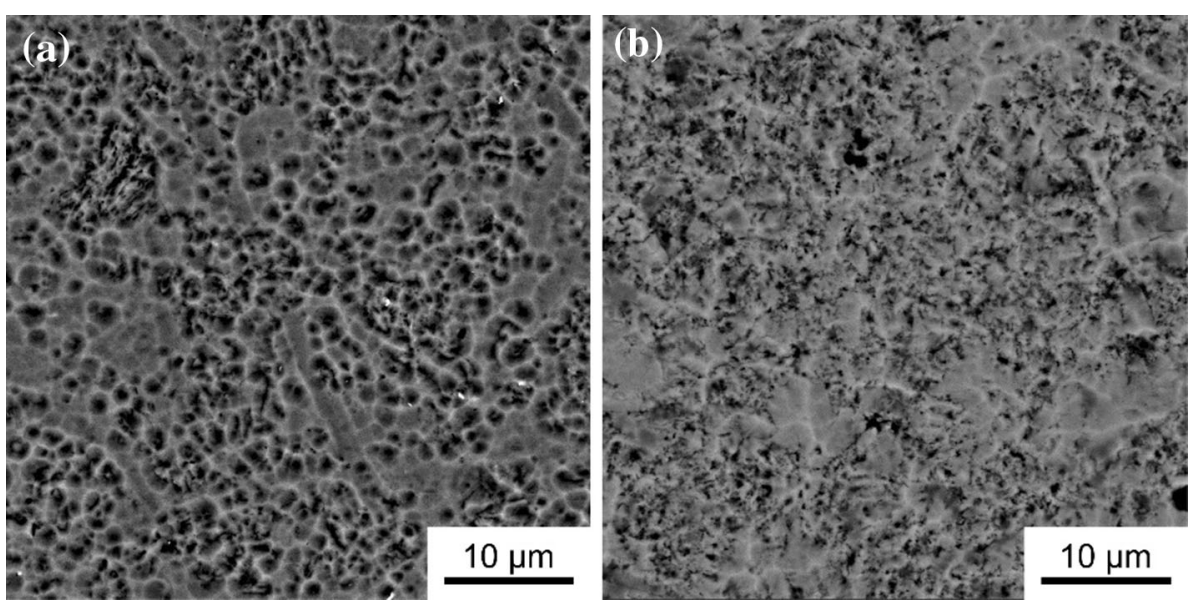
Table 3, show large variations in elastic moduli for nominally identical materials. This holds also if our values are included. The reported increase of the Young's modulus of the $\mathrm{Fe}_{90} \mathrm{Sc}_{10}$ nanoglass obtained by nanoindentation [13] is at present in disagreement with the $40 \%$ reduction found in this study. In our view, this finding must originate from the details and the differences in synthesis and processing history which have manifested in the investigated specimens. Thus, further efforts are necessary to find out whether there are preparation routes for nanoglasses which yield elastic data representing intrinsic values.

Regarding the $\mathrm{CuZr}$ systems, even a compaction pressure of $6 \mathrm{GPa}$ changes the elastic properties only marginally compared with the data for the $1.3 \mathrm{GPa}$ compacted material. Our results rather support the conclusion that the glass-glass interfacial regions of nanoglasses lead to reduced elastic moduli compared to the metallic glass counterparts.

Acknowledgements This paper is dedicated to the memory of Dr. Baldev Raj, Department head and former director of Indira Gandhi Centre of Atomic Research (IGCAR), Kalpakkam, India, who passed away in January 2018. Beside his achievements as a scientist and manager of science groups, Dr. Raj very much fostered international exchange and collaboration, in particular Indo-German collaboration. One of us (WA) is thankful for many years of fruitful interaction with Dr. Baldev Raj and with many colleagues of the research groups he headed at the IGCAR. The interaction and the exchange of scientists were made possible by projects within Indo-German collaboration in Material Science and Non-Destructive Testing and were financed by the International Bureau of the DLR in Cologne, Germany. We thank Jörg Schmauch for help in sample preparation and SEM and Nils Boussard for assistance in the density measurements. One of us $(\mathrm{HH})$ would like to acknowledge the financial support of the DFG under contract number HA1344/XX-2. SPS is very much thankful to Karlsruhe Institute of Technology (KIT) for the guest scientist award to carry out this work. Open Access funding provided by Projekt DEAL.

Open Access This article is licensed under a Creative Commons Attribution 4.0 International License, which permits use, sharing, adaptation, distribution and reproduction in any medium or format, as long as you give appropriate credit to the original author(s) and the source, provide a link to the Creative Commons licence, and indicate if changes were made. The images or other third party material in this article are included in the article's Creative Commons licence, unless indicated otherwise in a credit line to the material. If material is not included in the article's Creative Commons licence and your intended use is not permitted by statutory regulation or exceeds the permitted use, you will need to obtain permission directly from the copyright holder. To view a copy of this licence, visit http://creativecommons.org/licenses/by/4.0/.

\section{Appendix A}

\section{Ultrasonic Electronics and Transducers}

As an rf-receiver, an amplifier with a 6-dB bandwidth 1-600 MHz made by MITEC in Hauppage, NY, USA, type
$\mathrm{Au} 101411217$ was employed for the wide-band and the narrow band system. The amplifier was protected from overload by two anti-parallel diodes. This system was previously been developed in order to detect very small defects in structural ceramic materials [42].

Furthermore, a prototype ultrasonic transmitter-receiver system from Krautkrämer-Branson was used. In this system, the excitation pulse of the transducer has amplitude of about $-100 \mathrm{~V}$ with a rise time of $2 \mathrm{~ns}$ and decay time of $10 \mathrm{~ns}$. An rf-amplifier with a bandwidth of $500 \mathrm{MHz}$ is integral part of this system.

For the wide-band excitation technique, the bandwidths of the transducers are appreciably smaller than the spectral width of the electrical impulse and the bandwidth of the receiver amplifier. This resulted in a quasi-rf-carrier excitation with a pulse length equal to the inverse bandwidth of the transducer. In this case, the accuracy of delay time measurements was reduced relative to the rf-carrier system [43]. The effect was small because the measured and expected relative bandwidths in the spectra of the pulses were of the order $4 \%$.

The transducers employed for the measurements reported here had center frequencies of up to $125 \mathrm{MHz}$ for longitudinal waves, and $20 \mathrm{MHz}$ for shear waves. The 6-dB bandwidths of the transducers were typically about $1 / 2$ the value of their center frequency. Their bandwidths were large enough to allow distinguishing echoes in sample as thin as $100 \mu \mathrm{m}$. The transducers employed were manufactured by Olympus (previously Panametrics). One transducer type was the custom made V2173 (serial number 614966). Its 6-dB bandwidth was $\approx 10 \mathrm{MHz}$ at a center frequency of $20 \mathrm{MHz}$. It is a so-called dual-probe consisting of two active piezoelectric elements producing extensional or transverse oscillations. The elements are mounted adjacent to each other on a glass delay line. The dual-probe type allows one to generate both longitudinal (L-port) as well as shear waves (S-port), and hence to measure longitudinal and shear wave velocities within one experimental run. Other probes for the generation of longitudinal waves were V2054 (100 MHz center frequency), V2062 (125 MHz center frequency), V214 BB (50 MHz center frequency), and $\mathrm{V} 213 \mathrm{BB}(30 \mathrm{MHz}$ center frequency). The shear wave delay-lines transducers were V222 BA-RM (20 MHz center frequency), V 2173 S-port (20 MHz center frequency), and V222 BB (20 MHz center frequency). The coupling medium was highly viscous honey in all cases. This allowed transmitting shear waves through the interfaces of the sample-delay lines.

Finally, there was dispersion in the signals which contributed to the inaccuracies. One part of the dispersion might have been caused by diffraction of the sound field. All our measurements were carried out within the near field of the transducers, partially within their extreme near field, 
i.e. $S<<1$. Here, $S$ is the normalized distance $S=z \lambda / a^{2}$ ( $z=L$ for double-ended or $z=2 L$ for single-ended) where $L$ is the propagation length in the sample, $\lambda$ is the wavelength of the ultrasonic wave, and $a$ is the radius of the ultrasonic beam at the point of entry to the sample. For our transducers, $S$ is of the order of $10^{-2}$ and the ensuing time delay [44] due to diffraction is of the order of $5 \times 10^{-3}$ radians corresponding to an additional delay of $\approx 0.4 \mathrm{~ns}$ which is much less than the other inaccuracies estimated above for the pulse-echo measurements. The thickness of the $\mathrm{Cu}_{58} \mathrm{Zr}_{42}$ sample was $0.450 \pm 0.001 \mathrm{~mm}$ in the center. The sample was barrel-shaped with a thickness of $0.25-0.33 \mathrm{~mm}$ at its edges. Therefore, the coupling medium was only spread over an area of diameter yielding $S \approx$ $5 \times 10^{-2}$ which entailed an additional inaccuracy in timeof-flight measurement of $2 \mathrm{~ns}$.

For the transmission experiments, a relative time difference due to diffraction caused by the differences in the sound velocities between the glass delay line and the metallic glasses might have occurred. Estimates showed that this effect could also be neglected because their velocities were quite similar $\left(v_{\mathrm{L}, \mathrm{SiO} 2}=5.9 \mathrm{~mm} / \mu \mathrm{s}\right.$ and $\left.v_{\mathrm{T}, \mathrm{SiO} 2}=3 \mathrm{~mm} / \mu \mathrm{s}\right)$.

\section{References}

1 Jing J, Kramer A, Birringer R, Gleiter $\mathrm{H}$ and Gonser U, J NonCryst Solids 113 (1989) 167.

2 Gleiter H, J Appl Crystallogr 24 (1991) 79.

3 Weissmüller J, Schubert P, Franz H, Birringer R and Gleiter H, in The Physics of Non Crystalline Solids, (eds) Pye L D, La Course W C, Stevens H J, Taylor \& Francis, London (1992), pp. 26-30.

4. Gleiter H, Acta Mater 56 (2008) 5875.

5. Gleiter H, Schimmel T and Hahn H, Nano Today 9 (2014) 17.

6. Witte R, Feng T, Fang J X, Fischer A, Ghafari M, Kruk R, Brand R A, Wang D, Hahn H and Gleiter H, Appl Phys Lett 103 (2013) 073106.

7. Stoesser A, Ghafari M, Kilmametov A, Gleiter H, Sakurai Y, Itou M, Kohara S, Hahn H and Kamali S, J Appl Phys 116 (2014) 134305.

8. Ghafari M, Hutchison W D, Campbell S J, Gleiter H, Hahn H and Feng T, J Phys Condens Matter 30 (2018) 025702.

9 Turek I and Hafner J, Phys Rev B 46 (1992) 247.

10. Becker C and Hafner J, Phys Rev B 50 (1994) 3913.

11. Zukowski E, Cooper M J, Timms D N, Armstrong R, Itoh F, Sakurai H, Tanaka Y, Ito M, Kawata H and Bateson R, J Phys Soc Jpn 63 (1994) 3838.

12. Sakai N, Mater Sci Forum 105 (1992) 431.

13. Franke O, Leisen D, Gleiter $\mathrm{H}$ and Hahn H, J Mater Res 29 (2014) 1210.

14. Sakmurai Y, Tanaka Y, Ohata T, Watanabe Y, Nanao S, Ushigami Y, Iwazumi T, Kawata H and Shiotani N, J Phys Condens Matter 6 (1994) 9469.

15. Chen N, Louzguine-Luzgin D V, Xie G Q, Sharma P, Perepezko J H, Esashi M, Yavari A R and Inoue A, Nanotechnology 24 (2013) 045610 .
16. Chen N, Frank R, Asao N, Louzguine-Luzgin D V, Sharma P, Wang J Q, Xie G Q, Ishikawa Y, Hatakeyama N, Lin Y C, Esashi M, Yamamoto Y and Inoue A, Acta Mater 59 (2011) 6433.

17. Yang B and Nieh T G, Acta Mater 55 (2007) 295.

18. Song S X, Jang J S C, Huang J C and Nieh T G, Intermetallics $\mathbf{1 8}$ (2010) 702.

19. Rose J L, Ultrasonic waves in solid media, Cambridge University Press, Cambridge (1999).

20. Eisenmenger W and Haardt M, Solid State Commun 41 (1982) 917.

21. Truell R, Elbaum C and Chick B B, Ultrasonic methods in solid state physics, Academic Press, New York (1969).

22. Wolfenden A, Dynamic elastic modulus measurements in materials, American Society for Testing and Materials, Philadelphia, PA 19103, USA (1990)

23. Thomsen C, Grahn H T, Maris H J and Tauc J, Phys Rev B 34 (1986) 4129.

24. Hurley D H, Wright O B, Matsuda O, Gusev V E and Kolosov O V, Ultrasonics 38 (2000) 470.

25. Hoffmann M and Birringer R, Acta Mater 44 (1996) 2729.

26. Künzi H U, Mechanical properties of metallic glasses, (eds) Beck $\mathrm{H}$ and Güntherodt H J, in Glassy Metals II, Springer, New York (1983), p. 169.

27. Sun Y H, Concustell A and Greer A L, Nat Rev Mater 1 (2016) UNSP 16039.

28. Phani K K and Niyogi S K, J Mater Sci Lett 6 (1987) 511.

29. Phani K K and Niyogi S K, J Mater Sci 22 (1987) 257.

30. Panakkal J P, Willems H and Arnold W, J Mater Sci 25 (1990) 1397.

31. Roberts A P and Garboczi E J, J Am Ceram Soc 83 (2000) 3041.

32. Liu W-H, Sun B A, Gleiter H, Lan S, Tong Y, Wang X-L, Hahn H, Yang Y, Kai J-J and Liu C T, Nano Lett 18 (2018) 4188.

33. Xu D H, Lohwongwatana B, Duan G, Johnson W L and Garland C, Acta Mater 52 (2004) 2621.

34. Davis L A, Chou C-P, Tanner L E and Ray R, Scr Metall 10 (1976) 937.

35. Kursumovic A and Scott M G, Appl Phys Lett 37 (1980) 620.

36. Nandam S H, Ivanisenko Y, Schwaiger R, Sniadecki Z, Mu X K, Wang D, Chellali R, Boll T, Kilmametov A, Bergfeldt T, Gleiter $\mathrm{H}$ and Hahn H, Acta Mater 136 (2017) 181.

37. Wang W H, Prog Mater Sci 57 (2012) 487.

38. Inoue A, Zhang W, Tsurui T, Yavari A R and Greer A L, Philos Mag Lett 85 (2005) 221.

39. Zhu Z W, Zhang H F, Sun W S, Ding B Z and Hu Z Q, Scr Mater 54 (2006) 1145.

40. Inoue A, Zhang W, Mater Trans 45 (2004) 584.

41. Chen H S and Krause J T, Scr Metall 11 (1977) 761.

42. Pangraz S, Simon H, Herzer R and Arnold W, Non-destructive evaluation of engineering ceramics by high-frequency acoustic techniques, (ed) Wade L H G, in Proc. 18th Int. Symp. Acoustical imaging, Plenum Press, New York, Santa Barbara, Ca., (1990) p 189

43. Kinra V K and Dayal V, Measurement of the modulus of dynamic elasticity of extremely thin (subwavelength) specimens, (ed) Wolfenden A, in Dynamic elastic modulus measurements in materials, American Society for Testing and Materials, Philadelphia, PA 19103, USA, (1990)

44. Papadakis E P, J Am Soc Acoust 49 (1970) 166.

Publisher's Note Springer Nature remains neutral with regard to jurisdictional claims in published maps and institutional affiliations. 